\title{
Attributes of Dental Trauma in a School Population with Active Sports Involvement
}

\author{
Anand Prabhu ${ }^{{ }^{*} \mathrm{ABCDEFG}}$, MDS; Arun Prasad Rao ${ }^{\mathrm{ABCDEG}}$, MDS; Mohan Govindarajan ${ }^{\mathrm{ACDEG}}$, MDS; \\ Venugopal Reddy $^{\text {ACDEG }}$, MDS; Ramalingam Krishnakumar ${ }^{\text {ACDEG }}$, MDS; Sugumaran Kaliyamoorthy ${ }^{\text {ACDEG }}$, MDS
}

Authors' Affiliation:

Department of Pedodontics and Preventive dentistry, Rajah Muthiah Dental College and Hospital, Annamalai University,

Annamalainagar, Tamilnadu. India

\begin{abstract}
Purpose: Dental trauma has become an important aspect of dental public health. The primary requisite before actively dealing with such problems is to describe the extent, distribution, and variables associated with the specific condition. The purpose of this study was to assess the prevalence and role of socioeconomic status and anatomic risk factors in traumatic dental injuries (TDI) to permanent anterior teeth in 10 to 16 year old Sainik (Army) school, children in India.
\end{abstract}

Methods: A cross-sectional study was conducted. Data was collected through a survey form and clinical examination. The permanent anterior teeth of four hundred and forty six male school children were examined for TDI. The socio-economic status, lip coverage and overjet were recorded. Statistical significance for the association between occurrence of TDI and the various risk factors was carried out.

Results: The prevalence of TDI to permanent anterior teeth was $23.8 \%$. A large number of injuries occurred during participation in sports. Inadequate lip coverage and a large maxillary overjet were identified as important predictors for dental trauma.

Conclusion: A high prevalence of dental trauma was observed in the study population suggestive of low awareness regarding the cause, effects and prevention of the condition.

Key Words: Traumatic Dental Injuries; Overjet; Lip Competence; Anterior Teeth Trauma; Socioeconomic Status

Asian Journal of Sports Medicine, Volume 4 (Number 3), September 2013, Pages: 190-194

\section{INTRODUCTION}

$\mathrm{T}$ raumatic dental injuries (TDI) can become an important public health problem not only because their prevalence is relatively high but also because they have substantial impact on children's daily life ${ }^{[1]}$.

The prevalence of dental trauma in highschool children ranged between 6 per cent in an Australian study ${ }^{[2]}$ to 34 per cent in an English study ${ }^{[3]}$. Studies on prevalence of TDI in India report $14.9 \%$ in 14-16 year National Cadet Corps (NCC) children ${ }^{[4]} ; 13.80 \%$ in 8-14 year South Kanara children ${ }^{[5]}$ and $10.13 \%$ in Chidambaram school children ${ }^{[6]}$. Trauma are more than doubled in children with overjet of $3.5 \mathrm{~mm}$ and larger ${ }^{[7-9]}$.
The method error for the trauma scale ${ }^{[10]}$, method of recording overjet ${ }^{[4]}$ and lip coverage ${ }^{[11]}$ has been previously tested and it has been established as acceptable.

Sainik School Udumalpet is an English medium, residential school for boys providing public school education with a military bias, managed by Ministry of Defence, Government of India. The aim of the school is to prepare the boys academically, physically and psychologically for entry into the National Defence Academy or other walks of life. These children regularly participate in activities like rock climbing, rafting, cycling expedition, trekking, games and sports like hockey, football, basketball, volleyball, cross country and athletics. In addition, there is also an 
obstacle course, horse riding facilities and swimming pool facilities. This provided an ideal opportunity to test the study objective of assessing trauma to permanent teeth in a high risk behaviour group with increased participation in sports, recreational and physical activity.

\section{METHODS AND SUBJECTS}

A cross-sectional study was conducted on 10 to 16 year old school children of Sainik school, Udumalpet in July 2009. Exclusion criteria for the study were:

1) Structural loss or complete tooth loss due to caries

2) Absence of developmental anomalies of teeth which can weaken the tooth structure

3) Children undergoing orthodontic therapy

A total of 458 students of the abovementioned age group were present in the school, all of whom agreed to participate in the study. However only 446 or $97.3 \%$ of the original total students were selected for the final study as the remaining 12 students fell in the exclusion criteria.

In the present study, permanent anterior teeth in the maxillary and mandibular arch were examined for TDI. Anterior teeth were selected for this study because it has been reported that the majority of dental injuries involve the anterior teeth ${ }^{[12]}$. The present study was conducted in field circumstances without optimal conditions for diagnosis (dental records, optical transillumination, radiographs, etc). The present study used the trauma classification (Table 1) given by Sgan Cohen et al ${ }^{[10]}$.
The evaluation of Lip competency/coverage took place at the beginning of the clinical examination without the child noticing the observation. Adequate lip coverage was defined as the upper lip completely covering the upper incisors in the resting position, whereas inadequate lip coverage was considered when the upper lip did not completely cover the upper incisors in the resting position ${ }^{[11]}$.

A community periodontal index style periodontal probe was used to measure overjet. Its markings were located at $3.5 \mathrm{~mm}$ and $5.5 \mathrm{~mm}$ which facilitated the grouping of the subjects into ranges of 0-6.

The socio-economic status (SES) of the subjects' families was calculated according to the modified Prasad's classification for SES for an Indian population as given by AK Agarwal, using income of the parents to arrive at SES scores ${ }^{[13]}$. The SES of the study population was then correlated with trauma.

Data analysis was done using SPSS version 10. Statistical significance for the association between occurrence of TDI and the lip coverage was carried out using the Chi-square test and for SES and maxillary overjet was carried out with gamma test. The level of significance set was $P<0.05$.

\section{RESULTS}

A total of 106 (23.8\%) children of the 446 screened had TDI to permanent anterior teeth. A total of 166 traumatized permanent anterior teeth were identified among the children. Most commonly injured teeth were the maxillary right central incisors followed by the

Table 1: Trauma classification by Sgan Cohen et al ${ }^{[10]}$

$\begin{array}{cc}\begin{array}{c}\text { Trauma } \\ \text { score }\end{array} & \text { Description } \\ \mathbf{0} & \text { No evidence of trauma } \\ \mathbf{1} & \text { Trauma limited to enamel } \\ \mathbf{2} & \text { Trauma involving dentin } \\ \mathbf{3} & \text { Trauma involving the pulp } \\ \mathbf{4} & \text { Treated trauma, which had clearly involved at least the dentin and usually restored with a composite restoration } \\ \mathbf{5} & \text { Discoloration due to trauma (verified by interview) } \\ \mathbf{6} & \text { Avulsed tooth due to trauma (verified by interview) }\end{array}$


Table 2: Toothwise distribution of trauma and trauma scores in children with active sports involvement

$\begin{array}{lccccccc}\text { Trauma score } & \mathbf{1} & \mathbf{2} & \mathbf{3} & \mathbf{4} & \mathbf{5} & \mathbf{6} & \text { Total (N\%) } \\ \text { Maxillary right central incisor } & 41 & 21 & 1 & 1 & 1 & 1 & 66(39.8) \\ \text { Maxillary right lateral incisor } & 16 & 17 & 0 & 0 & 0 & 0 & 33(19.9) \\ \text { Maxillary left central incisor } & 20 & 21 & 1 & 0 & 0 & 0 & 42(25.3) \\ \text { Maxillary left lateral incisor } & 6 & 4 & 0 & 1 & 0 & 0 & 11(6.6) \\ \text { Other teeth } & 8 & 4 & 2 & 0 & 0 & 0 & 14(8.4) \\ \text { Total injured teeth } & 91(51.8) & 67(40.4) & 4(2.4) & 2(1.2) & 1(0.6) & 1(0.6) & 166(100)\end{array}$

Chi square value $=24.30 ; P$. value $=0.2$

maxillary left central incisors. Enamel fracture (type 1)

\section{DISCUSSION}

Young males who frequently participate in sports and physical activity were identified to be at a higher risk for the occurrence of anterior teeth injuries ${ }^{[4]}$. The increased participation in sports, recreational and physical activity may be the reason for increased prevalence of TDI among Sainik school, Udumalpet children as compared to similar other studies conducted in India ${ }^{[4,14,15]}$.

Fractures involving enamel were the commonest form of injuries, followed by fractures involving enamel and dentin, as reported in previous studies ${ }^{[16,17]}$.

The maxillary central incisors were the most commonly injured teeth in the present study in accordance with earlier studies ${ }^{[18,19]}$. The most likely cause for the maxillary central incisors being most commonly injured could be that they erupt earlier than maxillary lateral incisors and thus are at longer risk ${ }^{[19]}$.

In the present study more injuries were recorded in maxillary incisors than mandibular incisors. This could be because the non-rigid connection between the lower jaw and the cranial base lessens any impact to lower teeth ${ }^{[19]}$.

Table 4: Trauma distribution by Socioeconomic status

$\begin{array}{lc}\text { Cause } & \text { Frequency (\%) } \\ \text { Cannot recollect } & 23(22) \\ \text { Sports activity } & 62(58) \\ \text { Road traffic accident } & 2(2) \\ \text { Inadvertent fall } & 13(12) \\ \text { Impact with foreign objects } & 4(4) \\ \text { Fights } & 2(2) \\ \text { Total } & 106(100)\end{array}$

Chi square value $=152.45 ; P$. value $<0.0001$

\begin{tabular}{lccc} 
Risk factor & \multicolumn{2}{c}{ Trauma } & Total \\
Upper high & 59 & 191 & $250(56.1)$ \\
High & 37 & 108 & $145(32.5)$ \\
Upper middle & 7 & 35 & $42(9.4)$ \\
Lower middle & 3 & 6 & $9(2)$ \\
Poor & 0 & 0 & 0 \\
BPL & 0 & 0 & 0 \\
Total & $106(23.8 \%)$ & $340(76.2 \%)$ & $446(100 \%)$ \\
Gamma value $=0.009 ; P$. value $=0.9$ & &
\end{tabular}


Table 5: Trauma distribution by Lip coverage and Overjet

\begin{tabular}{llccc}
\multicolumn{2}{c}{ Anatomic risk factor } & \multicolumn{2}{c}{ Trauma } & Total \\
& Adequate & Yes & No & $339(76 \%)$ \\
Lip coverage & Inadequate & 70 & 303 & $107(24 \%)$ \\
& Total & $106(23.8 \%)$ & $340(76.2 \%)$ & $446(100 \%)$ \\
\multirow{5}{*}{ Overjet } & $<3.5 \mathrm{~mm}$ & 18 & 222 & $240(53.8 \%)$ \\
& 3.5 to $5.5 \mathrm{~mm}$ & 54 & 98 & $152(34.1 \%)$ \\
& $>5.5 \mathrm{~mm}$ & 34 & 20 & $54(12.1 \%)$ \\
& Total & $106(23.8 \%)$ & $340(76.2 \%)$ & $446(100 \%)$
\end{tabular}

Chi-square value $=134.80 ; P$. value $<0.001 ;$ Gamma value $=-0.78$

Sport was the leading cause of injury as reported in an earlier study ${ }^{[4]}$ and the second most common cause was of unknown origin in accordance with Rai and Munshi ${ }^{[5]}$. The most probable cause for this could be the retrospective nature of the study and the slight nature of trauma (enamel fracture) recorded in the study ${ }^{[7]}$.

The peak incidence of TDI in the present study was in the age group of 10 to 13 years. Children are usually more active in this period of life and often lack motoric coordination because of their developmental stage. For this reason they often could not precisely evaluate velocity and danger. As they grew up the proneness to TDI significantly reduced ${ }^{[20]}$.

The association between TDI and SES was not significant. This might be due to the predominance of children from high socioeconomic categories. Perhaps psychosocial factors such as child's behavior, family structure and family function not selected in this study may be pertinent ${ }^{[21]}$.

When trauma prevalence in the individuals with inadequate lip coverage was compared with those with adequate lip coverage, there was a statistically significant association found $(P<0.001)$ as reported previously ${ }^{[4,8,11]}$. Lips provide protection to anterior teeth by avoiding excessive exposure of these teeth and thus a lack of lip coverage infer a greater risk of TDI in children $^{[11]}$.

As in previous studies a statistically significant association was found between the occurrence of anterior tooth injury and increasing overjet ${ }^{[4]}$. The most probable cause for this could be that the increased overjet would result in more forwardly placed anterior teeth and this more prominent position in turn would make these teeth more vulnerable for trauma.

\section{CONCLUSION}

The high incidence of orofacial injuries needs to be minimized for which the following guidelines are advocated:

1) Routinely conduct screening camps in schools to identify children who are at risk for dental trauma and inform parents about the risks of such injuries.

2) Improve knowledge of TDI and its emergency management among school teachers.

3) Mandatory use of mouthguards for contact sports.

4) Orthodontic correction for teeth at risk for TDI.

\section{ACKNOWLEDGMENTS}

The author would like to thank Dr Balakrishnan, Nandhini, Porkodi, Dr Sindhiya, and Dr Felix for their timely assistance and suggestions in the study. Permission for human study has been obtained from the review board of Rajah Muthiah Dental College, Annamalainagar.

Conflict of interests: None 


\section{REFERENCES}

[1] Traebert J, Peres MA, Blank V, et al. Prevalence of traumatic dental injury and associated factors among 12-year-old school children in Florianopolis, Brazil. Dental Traumatology 2003;19:15-8.

[2] Burton J, Pryke L, Rob M, Lawson JS. Traumatized anterior teeth amongst high school students in northern Sydney. Aust Dent J 1985;30:346-348.

[3] Hamilton FA, Hill FJ, Holloway PJ. An investigation of dentoalveolar trauma and its treatment in an adolescent population. Part 1: The prevalence and incidence of injuries and the extent and adequacy of treatment received. Br Dent J 1997;182:91-95.

[4] Baldava P, Anup N. Risk factors for traumatic dental injuries in an adolescent male population in India. J Contemp Dent Prac 2007; 8:35-42.

[5] Rai SB, Munshi AK. Traumatic injuries to the anterior teeth among South Kanara school children--a prevalence study. J Indian Soc Pedod Prev Dent 1998;16:44-51.

[6] Mohan Govindarajan, Venugopal N Reddy, Krishnakumar Ramalingam et al. Prevalence of traumatic dental injuries to the anterior teeth among three to thirteen-year-old school children of Tamilnadu. Contemp Clin Dent 2012;3:164-7.

[7] Petti S, Tarsitani G. Traumatic injuries to anterior teeth in Italian schoolchildren: prevalence and risk factors. Endod Dent Traumatol 1996;12:294-7.

[8] Burden DJ. An investigation of the association between overjet size, lip coverage and traumatic injuries to the maxillary incisors. Eur J Orthod 1995;17:513-7.

[9] Otuyemi OD. Traumatic anterior dental injuries related to incisor overjet and lip competence in 12 year old Nigerian children. Int $J$ Paed Dent 1994;4:81-5.

[10] Sgan-Cohen HD, Megnagi G, Jacobi Y. Dental trauma and its association with anatomic, behavioral, and social variables among fifth and sixth grade schoolchildren in Jerusalem. Community Dent Oral Epidemiol 2005;33:174-80.

[11] Flavia Robson, Maria Let1' cia, Ramos-Jorge et al. Prevalence and determining factors of traumatic injuries to primary teeth in preschool children. Dent Traumatol 2009;25:118-22.

[12] Caldas AF, Burgos ME. A retrospective study of traumatic dental injuries in a Brazilian dental trauma clinic. Dent Traumatol $2001 ; 17: 250-5$

[13] Agarwal AK. Social Classification: The Need to Update in the Present Scenario. Indian J Community Med 2008;33:50-1.

[14] Gupta K, Tandon S, Prabhu D. Traumatic injuries to the incisors in children of South Kanara district. A prevalence study. J Indian Soc Pedod Prev Dent 2002;20:107-13

[15] Pradeep S Tangade. The Prevalence of Anterior Teeth Fracture and its Relation to Malocclusion in 12 and 15 Year Old School Children Belgaum City India. J Oral Health Comm Dent 2007;1:7-11.

[16] Granville-Garcia AF, de Menezes VA, de Lira PIC. Dental trauma and associated factors in Brazilian preschoolers. Dent Traumatol 2006;22:318-22.

[17] Traebert J, Bittencourt DD, Peres KG et al. Etiology and rates of treatment of traumatic dental injuries among 12-year-old school children in a town in southern Brazil. Dent Traumatol 2006;22:173-8.

[18] Saroglu I, Sonmez H. The prevalence of traumatic injuries treated in the pedodontic clinic of Ankara University, Turkey, during 18 months. Dental Traumatology 2002;18:299-303.

[19] Cetinbaş T, Yildirim G, Sönmez H.. The relationship between sports activities and permanent incisor crown fractures in a group of school children aged 7-9 and 11-13 in Ankara, Turkey. Dent Traumatol 2008;24:532-6.

[20] Ivancic Jokic N, Bakarcic D, Fugosic V, et al. Dental trauma in children and young adults visiting a University Dental Clinic. Dent Traumatol 2009;25:84-7.

[21] Fakhruddin KS, Lawrence HP, Kenny DJ, Locker D. Etiology and environment of dental injuries in 12-to 14-year-old Ontario school children. Dent Traumatol 2008;24:305-8. 